\title{
Understanding the Determinants
}

\author{
of Success in Inter- \\ Organizational Information
}

\section{Sharing Initiatives: Results from a}

National Survey

by Djoko Sayogo

Submission date: 24-Mar-2019 07:52PM (UTC-0700)

Submission ID: 1099097008

File name:formation_sharing_initiatives_results_from_a_national_survey.pdf (924.56K)

Word count: 7588

Character count : 45818 


\section{Understanding the Determinants of Success in Inter-Organizational Information Sharing Initiatives: Results from a National Survey}

\author{
Djoko Sigit Sayogo \\ Center for Technology in Government \\ University at Albany, USA \\ dsayogo@ctg.albany.edu \\ University of Muhammadiyah at Malang, \\ Indonesia \\ dsayogo@umm.ac.id
}

\author{
J. Ramon Gil-Garcia \\ Center for Technology in Government \\ University at Albany, USA \\ jgil-garcia@ctg.albany.edu \\ Centro de Investigacion y Docencia Economicas \\ (CIDE), Mexico \\ joseramon.gil@cide.edu
}

\begin{abstract}
6BSTRACT
Inter-organizational collaboration and information sharing have the potential of generating great benefits to government agencies and other social actors dealing with complex public problems. However, these initiatives have proved to be difficult to implement and important challenges have been identified in previous studis. Existing literature deals with challenges and enablers as important success factors for inter-organizational information sharing initiatives. Most of this research is based on cases 1. $\mathrm{d}$ there are few quantitative empirical studies about this topic. Based on a national survey of govermment managers in two policy dom $7 \mathrm{~s}$ s, this study starts filling this gap by systematically identifying some important determinants of the success of interorganizational information sharing initiatives through quantitative empirical analysis. Our analysis suggests four factors as the key determinants of inter-organizational information sharing success. We found that the following variables are sta 1 tically significant and clearly influence the success of inter-organizational information sharing initiatives: (1) availability of financial resources, (2) formally appointe 11 project managers, (3) technical compatibility and (4) standards. As mentioned bef 1 , this is one of the first quantitative explorations and testing of success factors of inter-organizational information sharing in government settings and additional research is clearly needed.
\end{abstract}

\section{Categories and Subject Descriptors}

J.4. [Computer Applications]: Social and Behavioral Sciences Communication. C. 4 [Performance of Systems]: Design studies; Measurement techniques; Performance attributes

\section{General Terms}

Management, Economics, Human Factors, Verification

\footnotetext{
Permission to make digital or hard copies of all or part of this work for personal or classroom use is granted without fee provided that copies are not made or distributed for profit or commercial advantage and that copies bear this notice and the full citation on the first page. Copyrights for components of this work owned by others than ACM must be honored. Abstracting with credit is permitted. To copy otherwise, or republish, to post on servers or to redistribute to lists, requires prior specific permission and/or a fee. Request permissions from Permissions@acm.org.

dg.o '14, June 18 - 21 2014, Aguascalientes, Mexico

Copyright 2014 ACM 978-1-4503-2901-9/14/0\$15.00.

http://dx.doi.org/10.1145/2612733.2612739
}

\section{Keywords}

Information sharing, success factors, inter-organizational information sharing success, electronic government.

\section{INTRODUCTION}

Inter-organization information sharing and integration are regarded as practical and efficient tools for joint problem solving $[11,47]$, more so in public sector where the social problems become wicked and complex [38]. Effective inter-organizational information sharing has been associated with various benefits ranging from technical, organizational and political [11]. Interorganizational information sharing is deemed to improve efficiency by reducing the cost from shared development $[11,30]$, resources pooling and shared technical expertise [15,21], and reduce redundancy in terms of multiple data collection and storage [11]. Inter-organizational information sharing is also argued to improve public service delivery by facilitating interorganizational collaboration and coordination [51].

In addition, inter-organization information sharing often relies on collaborative work of diverse actors from different organizations performing different roles at distinct times. With such complex environment, inter-organizational information sharing is also facing numerous challenges. Some studies of inter-organization information sharing thus focus on understanding its challenges (for examples see $[18,20,41,42,43])$. Other studies take the discussion of the challenges and propose success factors of interagency information sharing based on the identified challenges $2^{21,49]}$

However, despite rich discussion on both the challenges and 2 ccess factors of inter-organizational information sharing, quantitative empirical examinations of the causal effects among various factors that influence 7 he success of these initiatives are scarce. This study identifies some important determinants of the success of inter-organizational information sharing initiatives based on the rigorous analysis of data from national survey. This study addre 5 ed two research questions as follow: a) what factors contribute to the success of inter-organizational information sharing initiatives? and b) Among th 1 ignificant determinants, which factors are more important in the success of interorganizational information sharing initiativ 4 ?

The data being analyzed in this study is from a national survey conducted by the Center for Technology in Government to 
understand the challenges and success factors of interorganizational information sharing initiatives from the perspective of public officers, consultants and NGOs. Based on this data, this paper focused its discussion on the determinants of interorganizational information sharing at the institutional level. The analysis results indicate four key factors - formally assigned project managers, availability of financial resources, interoperable standards and compatible technical infrastructure as determinants of inter-organizational information sharing success.

The rest of this paper is organized in six sections including the foregoing introduction. The second section discusses the determinants of inter-organization information sharing from previous studies including our hypotheses and preliminary research model. The third section outlines the data collection, the operationalization of the variables and the analysis technique. Section four presents the analysis results and section five discusses the findings from the analysis results. Finally, section six provides some concluding remarks and suggests areas for future research.

\section{THE DETERMINANTS OF SUCCESS IN CROSS-BOUNDARY INFORMATION SHARING INITIATIVES}

This section of the paper describes the main determinants of interorganizational information sharing already identified in the literature and group them in big categories similar to the proposal previously described. We argue that these categories are also useful to understand the determinants of the more specific initiatives that deal with cross-boundary information sharing and integration

To frame our discussion on the success factor of cross-boundary information sharing, in this study we adopt the concept of cross boundary information sharing from Gil-Garcia, Pardo \& Burke [19]. They define cross-boundary information sharing as a system that consists of four key components: trusted social networks, shared information, integrated data and interoperable technical infrastructure $[19$, p.196]. They further view cross boundary information sharing as the essential core underlying the sociotechnical system of cross-boundary collaboration. Thus, it is plausible to argue that success of cross-boundary information sharing is determined by socio-technical determinants. Andersen and Dawes [2] propose a framework to understand the determinants and aspects relevant to government information technology initiatives within the socio-technical perspectives. Their framework classifies the determinants into three interrelated categories, namely: technology, organization and policy. These three different categories reside within larger contexts, such as: economy or political environment [2].

\subsection{Technological and Informational Determinants}

The growing role of technology in government is central to cross boundary information sharing (CBIS). CBIS initiatives have achieved some promising benefits from the use of ICTs $[4,5,6,9,11,26]$. However, though technology is an important factor for CBIS, the expectation that technology creates new information sharing and integration capability oftentimes remains hype but comes to the reality only in some practices [41]. Interorganizational technological compatibility and interoperability affects the performance of CBIS to substantial extent. The technology context primarily and typically involves development of standards, platform and application interoperability, metadata, and use of algorithms $[3,16,21:-, 24,25,34,37,40,42,45,46]$. Aside from that, previous studies found that information security and protection significantly influence use within information sharing initiatives. Concems with information security create significant challenges in embracing and implementing cross-boundary information sharing as well [50].

\subsection{Organizational and Managerial Determinants}

A variety of managerial factors in organizational and interorganizational contexts could affect CBIS initiatives. From the organizational perspective, fundamental components of organizational settings (i.e., resource, structure, leadership, strategy and process) leverage CBIS. From the interorganizational perspective, lack of availability of financial resources is one of the most apparent reasons for failure in CBIS initiatives. Without financial resources, it will be extremely difficult to initiate and sustain collaboration that underlies sharing knowledge and information [18]. In addition, the differences in organizational resources are very important as a determinant of CBIS. Incompatibility between the technical resources of participating organizations represents also a major challenge.

Organizational structure is another important determinant of CBIS $[32,33]$. Structural characteristics of organizations including centralization, formalization, and other bureaucratic characteristics $[17,22]$ would influence communication channels and information flows within an organization or between organizations. Leadership also has a significant influence on CBIS $[12,13,14,19]$. Leadership for CBIS initiatives can be manifested through various mechanisms. For instance, positive top management support and active engagement, and attention by top management are enablers for CBIS $[28,37,44]$. In addition, previous studies have recognizes the importance of the involvement of external consultants [29], particularly information technology projects in the private sector [23]. Studies examining ERP (enterprise resource planning) implementation recognize the importance of external consultants for the success of the ERP implementation (e.g. Motwani, Mirchandani, Madan \& Gunasekaran [36]). There are some indications that the involvement of external consultant is also one of the main factors influencing interagency information sharing [39].

\subsection{Political and Policy Determinants}

The legal, regulatory and policy frameworks in which government agencies operate clearly influence information sharing and integration. In fact, the legal context is a basic condition for crossboundary information sharing [11,31]. Multi-organizational collaboration in the public sector needs institutional legitimacy, which commonly begins with law or regulation and is strengthened by the sponsorship of recognized authority or formal relationships among participants [10]. Legislation as a bolster for institutional legitimacy has a dual effect. Legislation can affect CBIS initiatives by creating governance conditions for better information sharing among different agencies.

On the other hand, most government activities are defined and funded through legislation that creates specific programs and assigns responsibility for those programs to specific agencies. Institutional legitimacy can also be derived from the involvement of top executives in the project. Pardo, Gil-Garcia \& Burke [41] argue that executive involvement affects governance structures in cross-boundary information sharing initiatives. The governance 
structure in tum provides institutional legitimacy for the managers or personnel in collaboration for inter-organizational information sharing [41].

The political environment around government agencies exerts strong institutional and situational influences on information sharing and integration initiatives [41]. Dawes et al [8] view political distance between the participating organizations as a contextual factor influencing organizational participation in information sharing. Given political distance (i.e., the gap, divergence and conflict in political interests, political philosophies, points of view and agendas), participants are less likely to establish and sustain their engagement in a network for information and knowledge sharing.

\subsection{Contextual Determinants}

Finally, the three types of determinants of cross-boundary information sharing are embedded in the context in which government organizations operate. This environment shapes how each of the determinants affects the success of cross-boundary information sharing initiatives. General socioeconomic and political environments, in particular, place constraints or promote CBIS initiatives $[15,40,48]$.

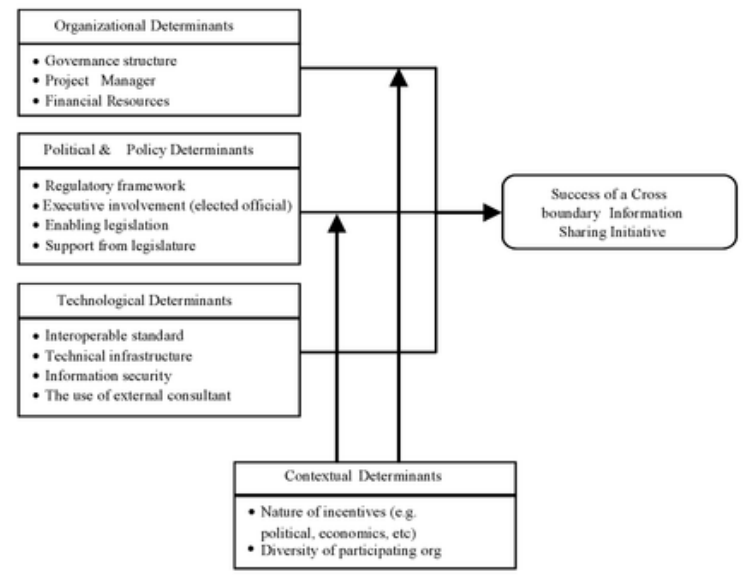

Figure 1. The Research Model

\subsection{Proposed Hypotheses and Research Model}

Drawing on previous studies on the success factors of interorganizational information sharing, this study identifies the following factors that influence the success of inter-organizational information sharing initiative as depicted in Figure 1. Using these factors as the basis, this study generates the following hypotheses.

a. Model 1. Political and Policy Determinants. Political and policy provide sponsorship and legitimacy that affect the success of the information sharing collaboration [10,11,31]. as such, this study hypothesize that:

Hypothesis 1: Political and policy determinants (including regulatory framework, involvement of top executives (elected official), legislation enabling the initiative and support from the legislature) significantly influence the success of crossboundary information sharing initiatives.

b. Model 2. Organizational \& Managerial Determinants. Fundamental components of organizational setting including leadership [12, 13, 14, 19], organizational structure [32,33] and resources/funding $[18,20,21]$ are indispensible for the success of interagency information sharing. Thus, it is hypothesized.

Hypothesis 2: Organizational and managerial determinants (including governance structure of the initiative, the existence of formally appointed project manager, the availability of financial resources and the involvement of external consultants in the project) significantly influence the success of crossboundary information sharing initiatives.

c. Model 3. Political and Organizational Determinants. Organizational and managerial determinants in interagency information sharing are contingent to the degree of political and policy determinants. Political contexts provide legitimacy and sponsorship that are both needed for the success of interagency information sharing $[10,11,31]$. Legitimacy and sponsorship assured the structure of collaboration and availability and continuity of funding. It is hypothesized.

Hypothesis 3: Political and policy determinants as well as organizational and managerial determinants significantly influence the success of cross-boundary information sharing initiatives.

d. Model 4. Technological Determinants. Technology, particularly information technology, is important factor for the success of interagency information sharing. Technology such as interoperable standard and platform, metadata and others are argued to affect the likelihood of interagency information sharing success $[3,16,21,24,40,42]$. As such, this study hypothesized.

Hypothesis 3: Technological and informational determinants (including compatibility in technical infrastructure, development of standards and information security) significantly influence the success of cross-boundary information sharing initiatives.

\section{DATA AND MEASUREMENTS}

This study analyzes data from a national survey conducted by the 6 nter for Technology in Government (CTG) in April 2008. The original random-sampled dataset consists of 173 responses with dem 4 raphic distribution as shown in table 1. After data cleaning, the analysis was based on $158-160$ responses and about $7-8 \%$ of the responses are dropped from the analysis due to missing values. Majority of survey respondents work at local governments (56\%), followed by state governments $(29 \%)$. These respondents majority have position as executive $(35 \%)$ or program managers $(35 \%)$. The proportion of male respondents was higher than female respondents by $16 \%$. In terms of year, almost all respondents have acquired some experiences working in their respective field. Only $3 \%$ of the respondents did not yet acquired some experience at the time of the survey.

Table 1. The Sample Distribution

\begin{tabular}{llr}
\hline & Categories & Proportion \\
\hline Employment & Federal Agencies & $5 \%$ \\
& Local Agencies & $56 \%$ \\
& State Agencies & $29 \%$ \\
& Private Entities & $3 \%$ \\
& NGOs & $4 \%$ \\
& Academics & $1 \%$ \\
Position & Other (e.g. independent & $2 \%$ \\
& consultant) & \\
& Executive & $35 \%$ \\
& IT Manager & $12 \%$ \\
& IT Staff & $1 \%$ \\
& Program Manager & $35 \%$
\end{tabular}


Program Staff

Administrative Staff

Initiative's boundary

\section{Across units}

Across agencies within the same level

Across levels of government Across one level of govt. with non-government organizations Across multi-level of govt.

with non-government organization

Other (e.g. multi-nationals)

Primary

Initiative

Coordinator

Federal government

State government

Local government

Private entities

Non-profit organization

Other (e.g. council of

government)

Years of

Experience

0 year

$1-5$ years

$6-15$ years

$16-25$ years

$>25$ years

Sex

Female

Male

The set of explanatory variables includes various factors: enabling legislation, regulatory framework, support from legislature, executive (elected official) involvement, nature of incentives, diversity of participating organizations, network governance structure, hierarchical governance structure, formally assigned project manager, availability of financial resources, the use of external consultants, interoperable standards, technical infrastructure, and information security. Except from regulatory framework and executive involvement, these variables are measured using a 7-level likert scale. The regulatory framework and executive involvement variable is a composite variable measured using the predicted score after running principal component analysis. The reliability of the composite of regulatory framework measured using Cronbach Alpha is 0.926 and for executive involvement is 0.809 . The value of Cronbach Alpha for both variables is above the accepted cut-off value of 0.7 indicating that these variables are reliable. The descriptive statistics of the explanatory variables is presented in Table 2 .

Table 2. Descriptive Statistics of the Variables

\begin{tabular}{llcc}
\hline \multicolumn{1}{c}{ Explanatory Variables } & \multicolumn{1}{c}{$\boldsymbol{M}$} & $S D$ \\
\hline $\begin{array}{l}\text { Success of the Inter- } \\
\text { Organizational Information }\end{array}$ & {$[\mathrm{SUC}]$} & 5.78 & 1.43 \\
Sharing Initiative & & & \\
Regulatory framework & {$[\mathrm{RG}]$} & $4.79 \mathrm{e}^{-09}$ & 1.36 \\
Executive involvement & {$[\mathrm{EI}]$} & $-3.90 \mathrm{e}^{-09}$ & 1.29 \\
Enabling Legislation & {$[\mathrm{EL}]$} & 3.11 & 2.24 \\
Support from legislature & {$[\mathrm{SL}]$} & 3.64 & 1.98 \\
Diversity of participating & {$[\mathrm{DO}]$} & 5.56 & 1.62 \\
organization & & & \\
Nature of Incentives & {$[\mathrm{NIC}]$} & 3.99 & 2.45 \\
Network governance structure & {$[\mathrm{NG}]$} & 5.12 & 1.75
\end{tabular}

\begin{tabular}{llll}
$\begin{array}{l}\text { Hierarchical governance } \\
\text { structure }\end{array}$ & {$[\mathrm{HG}]$} & 2.17 & 1.85 \\
$\begin{array}{l}\text { Formally assigned initiative } \\
\text { manager }\end{array}$ & {$[\mathrm{PM}]$} & 5.56 & 1.49 \\
$\begin{array}{l}\text { Availability of financial } \\
\text { resources }\end{array}$ & {$[\mathrm{FR}]$} & 4.56 & 1.63 \\
$\begin{array}{l}\text { The use of external consultant } \\
\begin{array}{l}\text { Interoperable standard } \\
\text { Technical infrastructure }\end{array}\end{array}$ & {$[\mathrm{EC}]$} & 3.98 & 2.37 \\
Information security & {$[\mathrm{TCS}]$} & 5.33 & 1.85 \\
& {$[\mathrm{TSE}]$} & 4.74 & 1.57 \\
\hline
\end{tabular}

The dependent variable of this study is the success of the interorganizational information sharing initiatives. This variable measures the extent to which the respondents identified the initiative in which they were involved as a success. For the analysis, we included inter-agency information sharing initiatives only (initiatives with the participation of two of more organizations). The measurement of these variables ranges from 1 as indication of "not a success" to 7 as indication to "success to a great extent".

Normally, seven-point scales can be considered as continuous variables. We follow this convention in this paper. In order to test the hypotheses described before, this study employs multivariate regression analysis.

\section{ANALYSIS AND RESULTS}

Based on a review of previous literature, this study presents a theoretical model that includes variables that have been identified as influencing inter-organizational information sharing. Our regression analysis provides empirical quantitative evidence for a few of these important relationships. This section shows the main resul $t_{3}$ rom our analyses and starts discussing their implications.

The pair $3 \mathrm{e}$ correlation matrix presented in Table 3 merits analytical attention before we analyze the regression results. Table 3 indicates that variables related to political and policy determinants, organizational determinants and technological determinants all significantly correlate to the success of the interorganizational information sharing initiative. The existence of regulatory framework $(0.23)$, executive involvement $(0.35)$ and support of 5 egislature $(0.18)$ has positive and significant correlation to the success of information sharing initiatives. As expected, the availability of financial resources $(0.45)$ and formally appointed project managers $(0.41)$ are also crucial for the success of the initiative. Table 3 also shows that three technological factors - interoperable standard $(0.33)$, technical infrastructure (0.43) and information security (0.17) are all significantly correlated with the success of inter-organizational information sharing initiatives. To test whether this independent significant relationship of each factor persists when considering the combined effect of all factors and their respective unique variance, we run robust multivariate regression analysis to mitigate the issue of heteroscedasticity (Table 4).

Consistently with the theoretical model developed from previous studies, Table 4 presents the regression results for five statistical models. Three models, namely: political and policy (model 1), organizational (model 2) and technological (model 4) regress each category of the determinants to the success of information sharing initiative individually. Model 3 assess whether the impact of policy persists with the inclusion of organizational factors. Finally, model 5 measures the influence of organization, policy and technology determinants when combined together in one single model. 
a. Political and policy variables as determinants of the success of inter-organizational information sharing initiatives

When only considering the political and policy aspects, the results in model 1 indicate that executive involvement emerges as significant predictor of inter-organizational information sharing success with coefficient of 0.32 (t-value 2.52 ; p-value 0.013 ), controlling for the other variables. Executive involvement is necessary to induce and/or strengthened institutional legitimacy. The executive provide sponsorship of recognized authority for the inter-organizational collaboration (Dawes \& Prefontaine, 2003) as well as ensuring support for resources needed for the collaboration. Table 4 also shows that other institutional predictors - regulatory framework, enabling legislation and support from legislature - are not statistically significant. We argue that this is due to the nature of incentives influencing the pursuance of the inter-organizational information sharing initiatives. project manager \{coeff. 0.35; (t-value 3.58; p-value 0.000 ) \} and availability of financial resources \{(coeff. 0.29; (t-value 3.81 pvalue 0.000$)\}$ - significantly explain the success of interorganizational information sharing initiatives. The results also indicate that external consultants is not a significant predictor.

We argue that the existent of formally appointed project managers contributes in making coordination of the inter-organizational sharing effort more efficient. Btter coordination could be seen as a very important factor for the success of inter-organizational information sharing initiatives. The availability of financial resources is positive and significant for the success of the initiative. As expected, the availability of resources is needed to sustain the collaboration for the inter-organizational information sharing efforts and to move the initiative forward. The R2 of model 2 is 0.31 indicating that the model explains $31 \%$ of the variation in the dependent variable, which is better than model 1.

Table 3. Pairwise Correlation Matrix

\begin{tabular}{|c|c|c|c|c|c|c|c|c|c|c|c|c|c|c|c|}
\hline & RG & EI & NIC & EL & SL & DO & $\mathrm{NG}$ & $\mathrm{HG}$ & PM & $\mathrm{FR}$ & $\mathrm{EC}$ & IOS & TCI & ISE & SUC \\
\hline RG & 1.00 & & & & & & & & & & & & & & \\
\hline EI & 0.30 & 1.00 & & & & & & & & & & & & & \\
\hline NIC & 0.09 & -0.02 & 1.00 & & & & & & & & & & & & \\
\hline EL & 0.36 & 0.06 & 0.23 & 1.00 & & & & & & & & & & & \\
\hline SL & 0.34 & 0.19 & 0.33 & 0.28 & 1.00 & & & & & & & & & & \\
\hline DO & 0.21 & 0.20 & 0.09 & 0.23 & 0.06 & 1.00 & & & & & & & & & \\
\hline NG & 0.14 & 0.19 & 0.02 & 0.01 & 0.09 & 0.08 & 1.00 & & & & & & & & \\
\hline HG & 0.26 & 0.12 & 0.25 & 0.14 & 0.41 & 0.08 & -0.16 & 1.00 & & & & & & & \\
\hline PM & 0.36 & 0.36 & -0.06 & 0.19 & 0.23 & 0.18 & 0.18 & 0.17 & 1.00 & & & & & & \\
\hline FR & 0.10 & 0.30 & 0.11 & 0.07 & 0.19 & 0.04 & -0.01 & 0.12 & 0.24 & 1.00 & & & & & \\
\hline $\mathrm{EC}$ & 0.16 & 0.27 & -0.03 & 0.05 & 0.20 & 0.16 & 0.19 & 0.10 & 0.28 & 0.09 & 1.00 & & & & \\
\hline IOS & 0.47 & 0.35 & 0.07 & 0.16 & 0.35 & 0.14 & 0.14 & 0.21 & 0.36 & 0.17 & 0.35 & 1.00 & & & \\
\hline TCI & 0.12 & 0.24 & -0.09 & -0.02 & 0.06 & 0.05 & 0.18 & 0.07 & 0.23 & 0.36 & 0.22 & 0.17 & 1.00 & & \\
\hline ISE & 0.19 & 0.09 & 0.03 & 0.10 & 0.06 & 0.18 & 0.03 & 0.06 & 0.22 & 0.03 & 0.25 & 0.25 & 0.07 & 1.00 & \\
\hline SUC & 0.23 & 0.35 & 0.03 & 0.13 & 0.18 & 0.12 & 0.14 & 0.06 & 0.45 & 0.41 & 0.12 & 0.33 & 0.43 & 0.17 & 1.00 \\
\hline
\end{tabular}

In fact, the descriptive statistics indicate that $52 \%$ of respondents stated that the initiative was not started because of special events such as new legislation, a crisis or an election. Thus, we can infer that many of the initiatives were enacted as part of a general strategy of the agencies involved and not due to special events. On the other hand, the R2 of model 1 is only 0.11 indicating that the variables included in the model only explain $11 \%$ of the variation in the dependent variable. This clearly shows that there are other important variables that can further explain the variation and are currently not included.

b. Organizational variables as determinants of the success of inter-organizational information sharing initiativ 5

We also examine the influence of organizational variables on the success of inter-organizational information sharing. Model 2 tests the influence of governance structure - network and hierarchy, formally appointed project managers and the availability of financial resources to the success of inter-organizational information sharing. The results indicate that two predictors -
Model 3 combines the variables in model 1 and model 2. The results are explained in the following section.

c. 10litical, policy, and organizational variables as determinants of the success of inter-organizational information sharing initiatives

As shown in Table 4, combining policy and organizational variables did not increase the explanatory power of the model or change the significance of any of the predictors. The inclusion of organizational determinants renders the executive involvement not significant (see model 3). On the other hand, the inclusion of political and policy determinants did not change the explanator 6 power of formally appointed project managers \{coeff. 0.306; (tvalue $3.31 ; \mathrm{p}$-value $(600)\}$ and availability of financial resources \{coeff. 0.270; (t-value 3.40; p-value 0.000 )\}; both still positive and significant (see model 3 ). It seems that the impact of political and policy variables takes time and their influence is mediated by organizational variables. 


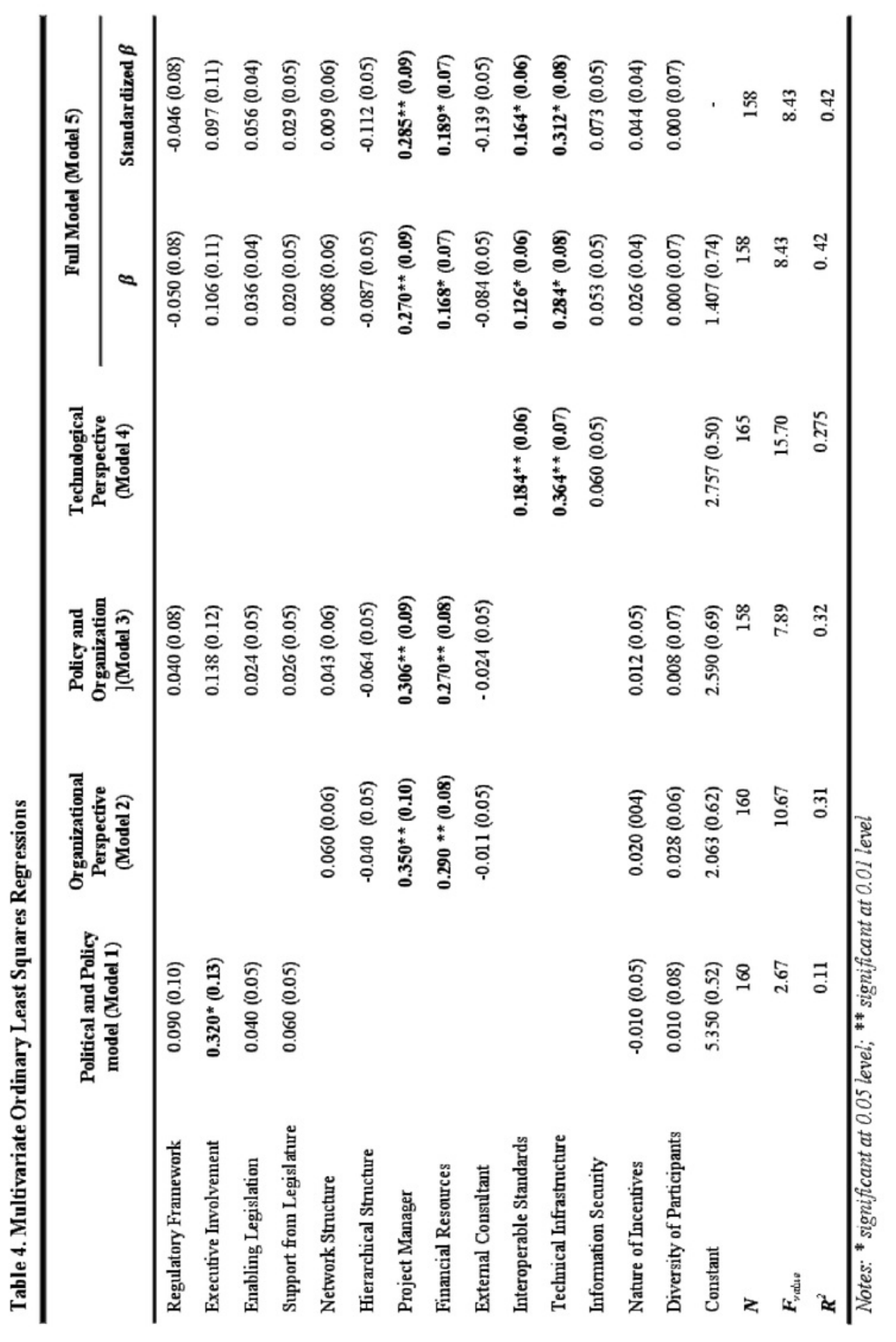


In addition, information sharing is seen by the respondents as part of their day to day operations. Survey result indicate that more than $60 \%$ of the initiatives are at the local government level and more than $50 \%$ of the respondents are from local governments (see Table 1). Consequently, an analysis of longitudinal data might provide better understanding on the impact of policy and political variables determinants. As mentioned before, executive involvement lost its significance in this third model. This could be because $52 \%$ of the respondents regarded their initiatives as enacted as part of a more general strategy of the agencies. Thus, the role of the executives is not as crucial as the formal appointment of project managers and the availability of financial resources.

d. Technological variables as determinants of the success of inter-organizational information sharing initiatives

In model 4, w5 5 ested the impact of technological variables in influencing the success of inter-organizational information sharing initiatives. The results in Table 4 indicate that the existence of standards \{coeff. 0.184; (t-value 3.05; p-value 0.001 )\} and technical infrastructure \{coeff 10.364; (t-value 4.90; p-value $0.000)\}$ significantly influence the success of inter-organizational information sharing initiatives. This result is consistent with previous studies that argue for the importance of interoperable standards and technological infrastructure compatibility (Bekkers, 2009; Ferro, 2010; Gil-Garcia \& Pardo, 2005; Gottchalk, 2009). The R2 of model 4 is 0.275 indicating that the model explains $27.5 \%$ of the variation in the dependent variable.

e. An Integrative Model: Political, policy, orga 5 tational and Technological variables as Determinants of success of inter-organizational information sharing initiatives

In model 5, we tested the impact of all different types of variables in explaining the success of inter-organizational information sharing initiatives. The results in model 5 are clearly consistent with the results from model 2 and mosi 4. There are four variables as significant predictor of the success of interorganizational information sharing initiatives. These variables are: formally assigned project managers \{coeff. 0.270; (t-value 3.10; p-value 0.002$)\}$, availability of financial resources \{coeff. 0.168 ; (t-value 2.24; p-value 0.05 )\}, interoperable standards \{coeff. 0.126; (t-value 1.95; p-value 0.05$)\}$, and technical infrastructure \{coeff. 0.284; (t-value 3.58; p-value 0.000 )\}. We also calculate the standardized (beta) coefficients to enable comparison among the variables in terms of their relative impact on the dependent variable. The beta coefficients for the four significant predictors, in order of importance, are: 0.285 for formally assigned project managers, 0.189 for availability of financial resources, 0.164 for interoperable standards, and 0.312 for technical infrastructure

f. The role of contextual determinants: Nature of incentives and diversity of participants

The analysis indicates that the two contextual variables - nature of incentives and diversity of participating organizations - did not emerge as statistically significant predictors of interorganizational information sharing success. This result might be due to the distribution of the level of government coordinating the inter-organizational information sharing initiative and the distribution of the initiative's boundary. The majority $(\geq 60 \%)$ of the initiative's primary coordinator are from local governments. More than half $(\geq 50 \%$ ) of the inter-organizational information sharing initiatives are across agencies at the same or different levels of government. Arguably, the complexity of the initiatives in terms of the diversity of participating organizations is not as high as for multi-organizational or multi-national initiatives. However, this is just a possible explanation and we inte1d to analyze the role of these and other contextual factors in the success of inter-organizational information sharing initiatives as part of our future research agenda.

\section{DISCUSSION: KEY FINDINGS}

In this study, we tested five different statistical models evaluating the determinants of success in inter-organizational information sharing initiatives. From these five models, the analysis results identify four factors as the key determinants.

a. Political and policy factors in the form of regulations or formal agreements about the initiative, existing legislation that made the initiative possible, and legislators supportin 1 he initiative are found to be not statistically significant for the success of inter-organizational information sharing initiatives. This finding is consistent with previous research such as the study by GilGarcia, Chengalur-Smith and Duchessi [43] who found that political barriers were not significantly affecting the expectation of benefits from users. In our case, we argue that the respondents consider information sharing initiatives as part of government operations and not an effort to fulfill political wish. In fact, more than half $(52 \%)$ of respondents stated the initiatives are not a consequence of special events. Therefore, these initiatives were enacted as part of general strategy of the agencies and were not seen as being directly affected by political appointees or legislators. In addition, being part of normal government operations, the initiatives, in the eyes of the respondents, were also not significantly affected by legislation, regulations, or specific agreements. Consequently, political and policy factors were seen as less important than organizational and technological factors.

b. As expected the results in 5 cate that availability of financial resources is crucial for the success of inter-organizational information sharing initiatives. As argued by Gharawi \& Dawes [18], the lack of financial support can be one of the most apparent reasons for failure in cross boundary information sharing initiatives. Financial resources are important for initiating and sustaining the collaboration in interorganizational projects [18]. Our findings provide evidence to support their argument and showca 5 that availability of financial resources contributes to the success of interorganizational information sharing initiatives. We also found the role of formally assigned project managers to be statistically significant, but we did not fin, the governance structure as a significant predictor of the success of inter-organizational information sharing initiatives. Inter-organization information sharing initiatives often rely on collaborative work involving various managers or personnel from diverse organizations performing different roles at different times. In addition to their roles in the collaborative work, these managers and/or other staff members still need to devote majority of their times to do their day-to-day work within the organization. According to Agranoff [1], typically public managers only spent $15-20 \%$ of their total work time in collaborative work. Considering the complexities of collaboration and the availability of managers/personnel's time, the existence of formally appointed project managers is crucial to sustain and make the collaboration successful. This could be also related to the fact that governance structure was found not to be a statistically significant predictor. The reason could be that the formally assigned project manager would work hard to sustain the 
collaboration regardless of the governance structure of the information sharing initiatives.

c. We found technic 7 interoperability to be an important factor for the success of inter-organizational information sharing initiatives, particularly the compatibility of technical infrastructure and the use of technical standards. These findings are consistent and support several previous studies - to name few - Bekkers [3]; Ferro \& Sorrentino [16]; Gil-Garcia \& Pardo [21]; Gottchalk [24]; McDermott [34]; Pardo et al. [40]; Pardo and Tayi [42]; Scholl and Klischewski [45] and others - that postulate the substantial roles of technical compatibility and interoperability in the form 1 standards, metadata, platform and application for the success of inter-organizational information sharing initiatives.

We also compared the relative importance of the four significant predictors, namely: formally assigned project manager, availability of financial resources, interoperability standards, and technical infrastructure. The beta coefficient of these variables indicates that the compatibility of technical infrastructure seems to be more important than other variables. Formally appointed project managers is perceived as the second most important determinants. This finding further support our argument that the respondents consider information sharing initiatives as part of government operations, maybe strategic initiatives, but not in the political sphere. Therefore, the variables related to government operations and the project itself, in terms of actors to sustain and move the initiative forward and the compatibility of legacy technical infrastructure, are regarded as crucial predictors for the success of these initiatives. In addition, this finding also suggests that there might be different determinants influencing the success of the initiatives depending on the nature of incentives underlying the initiation of the project. Future research should explore these potential differences in particular contexts.

\section{CONCLUDING REMARKS}

In this section we present what we think are the main contributions of this study to the theory and practice of interorganizational information sharing initiatives. The section is divided in two sub-sections. First, we present the contributions to theory, particularly the quantitative testing of the variables and the support generated about the ones that are statistically significant. Second, we argue that there are some practical lessons that could be derived from this study and applied to the management of inter-organizational information sharing initiatives.

\section{Contribution to Theory}

Our study contributes to understand the determinants of success of inter-organizational information sharing initiatives, and par 2 larly the critical role of formally assigned project managers in supporting and nurturing the efforts. The existence and statistically significance of a set of organizational and technological factors, such as project managers, financial 2 ources, technology infrastructure and interoperable standards, show the impact of these variables on the successful implementation of inter-organizational information sharing initiatives. Our finding of the significant role of formally assigned project managers supports and complements the results found in previous studies, such as Huxham \& Vangen [27] and McGuire [35]. For instance, Huxham \& Vangen [27] argued that leadership is often assigned from outside the control of the members of the collaboration. As such, they argued that leadership is often imposed upon the collaboration through structure and process. In addition, they posit that leading in collaborative work - such as inter-organizational information sharing - is highly resource consuming and require significant personal attention. Such attention and efforts are often lacking in the members of a collaborative, particularly public managers who need to spent $80-$ $85 \%$ of their total work time in their routine work [1]. Our finding thus highlight the importance of formally assigned project managers as a key actor to start and sustain the inter-organization information sharing collaboration given the complexities of these contexts. This finding points to an opportunity for further development of this research; that is to further understand the formation, emergence and role of project managers in sustaining and managing in 2 -organizational information sharing collaboration efforts. It is also important to clarify that some of these variables had been already identified in the literature, but quantitative explorations are still scarce. So another contribution of this study is to provide evidence for the generalization of the effect of certain variables, which could be thought of as importan in many other inter-organizational information sharing initiatives.

\subsection{Contribution to Practice}

Using the case study approach, previous studies have recognized technical incompatibility, lack of political support and lack of financial resources among the major challenges to implementing inter-organizational information sharing initiatives. Our research provides the quantitative empirical support for these key determinants. In particular this study underscores the significance of the role of project managers when implementing interorganizational information sharing. In this way, our findings provide implications for the developers and managers of of interorganizational information sharing that address the key factor to consider in managing the collaboration efforts to implement this type of initiatives. Hence, the initiators of inter-organizational information sharing initiatives could use this information in planning and structuring the collaborative efforts for implementing and managing these initiatives. The assignment of project managers specifically for the initiative could be seen as a very important first step. Securing enough financial resources is clearly also a lesson to be leamed and applied in interorganizational information sharing initiatives. This is clearly important for any project, but it is even more important for collaborative efforts, since they would die without the human and financial resources necessary to keep them moving forward. Finally, it is clear that information sharing is not possible without the necessary technical infrastructure and the used of interoperable technical standards. Organizations that want to share information need technical ways to be implement this and obtain some of the benefits in a more explicit way.

\subsection{Limitation and Future Research}

The findings are predomi 6 antly based on the national survey conducted in the US by the Center for Technology in Government. Whilst our study contributes to the understanding of the determinants of inter-organizational information sharing initiatives success, the hypotheses proposed in this study could be apply and tested to data from other countries. Such comparison could further ascertain the generality of the findings.

In addition, this study employs ordinary least square to infer the findings on the determinants of interagency information sharing success. Such technique is sufficient to analyze the direct causal relationship of two variables yet insufficient to account for the possible inter-relationship and interdependence among the determinants. Future research could further explore the possible 
recursive relationships among the variables by employing other techniques such as Structural Equation Modeling.

\section{Acknowledgment}

This work was partially supported by the National Science Foundation under grant \# ITR-0205152. Any opinions, findings, conclusions, or recommendations expressed in this material are those of the authors and do not necessarily reflect the views of the National Science Foundation.

\section{REFERENCES}

1. Agranoff, R. Inside Collaborative Networks: Ten Lessons for Public Managers. Public Administration Review 66, (2006), 56-65.

2. Andersen, D.F. and Dawes, S.S. Government Information Management: A Primer and Casebook. Prentice Hall, Englewood Cliffs, NJ, 1991.

3. Bekkers, V. Flexible information infrastructures in Dutch EGovernment collaboration arrangements: Experiences and policy implications. Government Information Quarterly 26, 1 (2009), 60-68.

4. Caffrey, L., ed. Information Sharing Between and Within Governments. Commonwealth Secretariat, 2000

5. Cresswell, A.B., Canestraro, D.S., Gil-Garcia, J., Pardo, T.A., and Schneider, C. Inter-organizational information integration: lessons from the field. (2004).

6. Cresswell, A.M., Pardo, T.A., Thompson, F., et al. Modeling intergovernmental collaboration: a system dynamics approach. Proceedings of the 35th Anmual Hawaii International Conference on System Sciences, 2002. HICSS, (2002), 10 pp.-

7. Dawes, S.S., Cresswell, A.M., and Pardo, T.A. From 'Need to Know' to 'Need to Share': Tangled Problems, Information Boundaries, and the Building of Public Sector Knowledge Networks. Public Administration Review 69, 3 (2009), 392 402.

8. Dawes, S.S., Gharawi, M., and Burke, B. Knowledge and Information Sharing in Transnational Knowledge Networks: A Contextual Perspective. 2011 44th Hawaii International Conference on System Sciences (HICSS), (2011), 1-10.

9. Dawes, S.S. and Pardo, T.A. Building Collaborative Digital Government Systems. In W.J.M. Jr and A.K. Elmagarmid, eds., Advances in Digital Government. Springer US, 2002, 259-273.

10. Dawes, S.S. and Prefontaine, L. Understanding new models of collaboration for delivering government services. Comminications of the ACM 46, 1 (2003), $40-42$.

11. Dawes, S.S. Interagency information sharing: Expected benefits, manageable risks. Journal of Policy Analysis and Management 15, 3 (1996), 377-394.

12. Demercivi, F., Thompson, F., and Bodor, T. Overcoming Cultural Barriers to Criminal Justice Information Integration After the 9-11 crisis. (2004).

13. Eglene, O., Dawes, S.S., and Schneider, C.A. Authority and Leadership Patterns in Public Sector Knowledge Networks. (2003), 91-113.

14. Eglene, O., Dawes, S.S., and Schneider, C.A. Authority and Leadership Patterns in Public Sector Knowledge Networks. The American Review of Public Administration 37, 1 (2007), 91-113.

15. Fedorowicz, J., Gogan, J.L., and Williams, C.B. A collaborative network for first responders: Lessons from the CapWIN case. Government Information Quarterly 24, 4 (2007), 785-807.
16. Ferro, E. and Sorrentino, M. Can intermunicipal collaboration help the diffusion of E-Government in peripheral areas? Evidence from Italy. Government Information Quarterly 27, 1 (2010), 17-25.

17. Fountain, J.E. Building the Virtual State: Information Technology and Institutional Change. Brookings Institution Press, Washington, DC, 2001.

18. Gharawi, M.A. and Dawes, S.S. Conceptualizing Knowledge and Information Sharing in Transnational Governmental Networks. (2010).

19. Gil-Garcia, J. R., Pardo, T. A., \& Burke, G. B. (2010) Conceptualizing information integration in govermment. In H. J. Schnoll (Ed.), E-government: Information, technology, and transformation: M.E. Sharpe.

20. Gil-Garcia, J.R., Chun, S.A., and Janssen, M. Govemment information sharing and integration: Combining the social and the technical. Information Polity 14, 1 (2009), 1-10.

21. Gil-Garcia, J.R. and Pardo, T.A. E-govemment success factors: Mapping practical tools to theoretical foundations Government Information Quarterly 22, 2 (2005), 187-216.

22. Gil-garcia, J.R. Enacting state websites: A mixed method study exploring e-government success in multiorganizational settings. University at Albany, State University of New, (2005).

23. Ginzberg, M.J. Early Diagnosis of MIS Implementation Failure: Promising Results and Unanswered Questions. Management Science 27, 4 (1981), 459-478.

24. Gottschalk, P. Maturity levels for interoperability in digital govemment. Government Information Quarterly 26, 1 (2009), 75-81.

25. Guijarro, L. Interoperability frameworks and enterprise architectures in e-government initiatives in Europe and the United States. Government Information Quarterly 24, 1 (2007), 89-101.

26. Hale, K. and McNeal, R. Technology, politics, and ecommerce: Internet sales tax and interstate cooperation Government Information Quarterly 28, 2 (2011), 262-270.

27. Huxham, C. and Vangen, S. Leadership In The Shaping And Implementation Of Collaboration Agendas: How Things Happen In A (Not Quite) Joined-Up World. Academy of Management Journal 43, 6 (2000), 1159-1175.

28. Jarvenpaa, S.L. and Ives, B. Executive Involvement and Participation in the Management of Information Technology. MIS Quarterly 15, 2 (1991), 205.

29. Kaarst-Brown, M.L. Five symbolic roles of the external consultant - Integrating change, power and symbolism. Journal of Organizational Change Management 12, 6 (1999), 540-561.

30. Kwon, H., Pardo, T.A., and Burke, G.B. Interorganizational collaboration and community building for the preservation of state government digital information: Lessons from NDIIPP state partnership initiative. Government Information Quarterly 26, 1 (2009), 186-192.

31. Landsbergen, D. and Wolken, G. Eliminating Legal and Policy Barriers to Interoperable Government Systems Association for Public Policy Analysis and Management, 1 30 .

32. Luna-Reyes, L.F., Gil-Garcia, J.R., and Cruz, C.B Collaborative digital government in Mexico: Some lessons from federal Web-based interorganizational information integration initiatives. Government Information Quarterly 24, 4 (2007), 808-826.

33. Luna-Reyes, L.F. and Gil-Garcia, J.R. Using institutional theory and dynamic simulation to understand complex e- 
Government phenomena. Government Information Quarterly 28, 3 (2011), 329-345.

34. McDermott, P. Building open government. Government Information Quarterly 27, 4 (2010), 401-413.

35. McGuire, M. Collaborative Public Management: Assessing What We Know and How We Know It. Public Administration Review 66, (2006), 33-43.

36. Motwani, J., Mirchandani, D., Madan, M., and Gunasekaran, A. Successful implementation of ERP projects: Evidence from two case studies. International Journal of Production Economics 75, 1-2 (2002), 83-96.

37. Murray, K.R. and Hsieh, I.K. Archiving Web-published materials: A needs assessment of librarians, researchers, and content providers. Government Information Quarterly 25, 1 (2008), 66-89.

38. O'Toole, L.J., Jr. Treating Networks Seriously: Practical and Research-Based Agendas in Public Administration. Public Administration Review 57, 1 (1997), 45-52.

39. Pardo, T.A., Burke, B., Gil-Garcia, J.R., and Guler, A. Clarity of Roles and Responsibilities in Government CrossBoundary Information Sharing Initiatives: Identifying the Determinants. Proceedings of the 5th International Conference on e-Government, (2009).

40. Pardo, T.A., Cresswell, A., and Burke, G.B. Modeling the social \& technical processes of interorganizational information integration. (2004).

41. Pardo, T.A., Gil-Garcia, J.R., and Burke, G.B. Information sharing and public health: A case-based look at the ICT expectations-reality gap. In A. Meijer, K. Boersma and P. Wagenaar, eds., ICTs, Citizens and Governance: After the Hype! IOS Press, 2009.

42. Pardo, T.A. and Tayi, G.K. Interorganizational information integration: A key enabler for digital government. Government Information Quarterly 24, 4 (2007), 691-715.

43. Ramon Gil-Garcia, J., Chengalur-Smith, I., and Duchessi, P. Collaborative e-Government: impediments and benefits of information-sharing projects in the public sector. European Journal of Information Systems 16, 2 (2007), 121-133.

44. Reddick, C.G. and Frank, H.A. The perceived impacts of egovernment on U.S. cities: A survey of Florida and Texas City managers. Government Information Quarterly 24, 3 (2007), 576-594.

45. Scholl, H.J. and Klischewski, R. E-Government Integration and Interoperability: Framing the Research Agenda. International Journal of Public Administration 30, 8-9 (2007), 889-920.

46. Schooley, B.L. and Horan, T.A. Towards end-to-end government performance management: Case study of interorganizational information integration in emergency medical services (EMS). Government Information Quarterly 24, 4 (2007), 755-784.

47. Tapscott, D. and Caston, A. Paradigm Shift: The New Promise of Information Technology. McGraw-Hill, Inc., New York, NY, USA, 1993

48. Wang, H., Song, Y., Hamilton, A., and Curwell, S. Urban information integration for advanced e-Planning in Europe. Government Information Quarterly 24, 4 (2007), 736-754.

49. Yang, T.M. and Maxwell, T.A. Information-sharing in public organizations: A literature review of interpersonal, intra-organizational and inter-organizational success factors Government Information Quarterly, (2011).

50. Yang, T.M. and Wu, Y.-J. What to Share and Why to Share? A Case Study of Cross- Boundary Information Sharing in Taiwan e-Government. Journal of Library \& Information Studies 11, 1 (2013), 25-53.

51. Zheng, L., Yang, T.-M., Pardo, T., and Jiang, Y. Understanding the "Boundary" in Information Sharing and Integration. 42nd Hawaii International Conference on System Sciences, 2009. HICSS '09, (2009), 1-10. 
Understanding the Determinants of Success in Inter-

Organizational Information Sharing Initiatives: Results from a National Survey

ORIGINALITY REPORT

$10 \%$

SIMILARITY INDEX
$5 \%$

INTERNET SOURCES
$11 \%$

PUBLICATIONS
$3 \%$

STUDENT PAPERS

PRIMARY SOURCES

1

Antonio Cordella, Frank Bannister, Peter

Parycek. "Introduction to Policies and

Strategies for Digital Government Minitrack",

2015 48th Hawaii International Conference on

System Sciences, 2015

Publication

2

Submitted to International Islamic University

Malaysia

Student Paper

3

"The effects of technology use on efficiency,

transparency, and corruption in municipal

governments : preliminary results from a

citizen perspective", Proceedings of the 16th

Annual International Conference on Digital

Government Research - dg o 15, 2015.

Publication 
6 "Electronic Government", Springer Nature, 2016 